\title{
Ultra-Rare Disorder in a Young Girl with Lipodystrophy: Analbuminemia
}

\author{
Aslı İnci ${ }^{1}$ (D) Burak Arslan ${ }^{2}$. İlyas Okur ${ }^{1} \cdot$ Gürsel Biberoğlu ${ }^{1} \cdot$ Merve Emecan Şanlı ${ }^{1} \cdot$ Ekin Aktaşoğlu ${ }^{1} \cdot$ Ayşe Kıllıç $^{1}$. \\ Leyla Tümer $^{1} \cdot$ Fatih Süheyl Ezgü $^{1}$
}

Received: 2 December 2020 / Accepted: 5 March 2021 / Published online: 27 April 2021

(C) Dr. K C Chaudhuri Foundation 2021

To the Editor: There are limited number of patients with congenital analbuminemia (CAA) with lipodystrophy in the literature and all of them have edema. An 8-y-old girl was admitted due to swelling of the fat tissues affecting the lower extremities without edema. Laboratory evaluation showed marked hypoalbuminemia $(0.19 \mathrm{~g} / \mathrm{dL}$, normal range: $3.63-$ 4.91 ), and significant increase in low-density lipoprotein cholesterol $(355 \mathrm{mg} / \mathrm{dL}$, normal range: $0-130)$ and total cholesterol $(443.6 \mathrm{mg} / \mathrm{dL}$, normal range: $0-200)$. Serum protein electrophoresis revealed the near absence of an albumin peak and compensatory increase in other proteins. The patient also had remarkable elevations in lipoprotein(a) and transferrin, suggesting CAA. Molecular analysis of the $A L B$ gene showed a homozygous mutation previously defined as IVS1+1G $>\mathrm{T}$ (c. $79+1 \mathrm{G}>\mathrm{T})$ studied by Sanger sequencing and confirmed with parental segregation [1].

A newborn premature baby who had respiratory distress syndrome and later on had pulmonary and gastrointestinal bleeding had the same mutation with our patient [1]. This baby revealed pretibial, dorsal, and gastrointestinal edema and was the severe form of the disease. There was no exact genotype-phenotype correlation in CAA. This previous report of CAA in a premature baby had the same mutation with our patient. Although the baby had the severe form of the disease with early onset findings, our patient was the milder form with only lipodystrophy and laboratory findings of the disease.

Aslı İnci

aslid.inci@gmail.com

1 Department of Pediatric Metabolism and Nutrition, Gazi University School of Medicine, Yenimahalle, Çankaya, 06520 Ankara, Turkey

2 Department of Clinical Biochemistry, Gazi University School of Medicine, Ankara, Turkey
While in the literature, nearly all patients with analbuminemia have edema, our patient did not have edema at the first presentation. Although there is no distinct pathophysiologic mechanism of lipodystrophy, possible mechanisms may be the absence of albumin from the skin, extrahepatic stimulation of lipogenesis, and lipid disturbances.

Until now, lipodystrophy has been reported in 6 adults at the time of diagnosis of CAA [2-4]. To the best of our knowledge, the present case represents the youngest known patient with lipodystrophy. It is exactly not known whether severe hypercholesterolemia leads to cardiovascular comorbidites or other diseases. This case of analbuminemia expands the differential diagnosis of lipodystrophy in children; thus, in the childhood period, albumin levels should be checked even in the absence of edema.

\section{Declarations}

Conflict of Interest None.

Informed Consent Informed consent was obtained from parents.

\section{References}

1. Caridi G, Dagnino M, Erdeve O, et al. Congenital analbuminemia caused by a novel aberrant splicing in the albumin gene. Biochem Med (Zagreb). 2014;24(1):151-8.

2. Kallee E. Bennhold's analbuminemia: a follow-up study of the two first cases (1953-1992). J Lab Clin Med. 1996;127:470-80.

3. Baldo-Enzi G, Baiocchi MR, Vigna G, Andrian C, Mosconi C, Fellin R. Analbuminemia: a natural model of metabolic compensatory systems. J Inherit Metab Dis. 1987;10:417-29.

4. Maugeais C, Braschi K, Ouguerram K, et al. Lipoprotein kinetics in patients with analbuminemia. Arterioscler Thromb Vasc Biol. 1997; 17:1369-75.

Publisher's Note Springer Nature remains neutral with regard to jurisdictional claims in published maps and institutional affiliations. 